\title{
Diminution and Magnification: Gothic Images in Jonathan Swift's Gulliver's Travels (1726)
}

Baker Mohammad Jamil Bani-Khair*

Department of English, Hashemite University, Jordan

Corresponding Author: Baker Mohammad Jamil Bani-Khair, E-mail: bakribakr@yahoo.com

\section{ARTICLE INFO}

Article history

Received: June 03, 2017

Accepted: September 08, 2017

Published: October 31, 2017

Volume: 8 Issue: 5

Advance access: October 2017

Conflicts of interest: Non

Funding: None

\section{Key words:}

Magnification

Diminution,

Dwarfs,

Gothic,

Sublime,

Phobia,

Fantasy,

Lilliputians

\begin{abstract}
This paper studies two significant techniques in Jonathon Swift's Gulliver's Travels (1726) which are diminution and magnification as influential devices which show gothic and supernatural images throughout the whole novel. The paper investigated and analyzed the supernatural images in terms of the gothic fantasy and its elements such as the ones that relate to the sublime, horror, and exotic images. The study concluded that the use of those two techniques of diminution and magnification tend to create several and various effects on the plot, characters, and the narrative development which increase the level of suspense in a critical framework.
\end{abstract}

\section{INTRODUCTION}

Diminution and magnification are the most dominant and recurrent techniques that Swift uses in Gulliver's Travels (1726). They are challenging techniques because they have several effects on the plot and action. In fact, both of these two elements have certain gothic, supernatural, and psychological implications which can be explained in completely different ways when we consider the idea of the social and political background of the novel. Studying Gulliver's Travels as a gothic fantasy brings about new ideas, and therefore contributes to the scholarship on Swift's Gulliver's Travels. Looking at Gulliver's Travels with some elements of the gothic in mind such as, the exotic, the sublime, the unconscious dream, and the self-vs. the other, can possibly lead to make a new research direction as I have done in this research paper. First of all, diminution and magnification in Gulliver's Travels explains the idea of a reversed reality which intersects with both imagination and Gothicism as well. For example, Gulliver as a character does not lose contact with the real world, rather his journeys are like a series of events in a remote exotic place while watching his own real world from a far, and also he does not lose the physical contact with his own people. Gulliver's imaginative world is based on a far-fetched fantasy that is not isolated from his own humanity, existence, or the boundaries of his own social life. We see images from the real world and the unreal as well in such a sublime imaginative fantasy. Gulliver's Travels, in the same time, matches Gothicism in the sense that it looks like an unconscious production that brings bizarre images and speculations about the human existence, which are quite rare in form and content.

\section{GULLIVER'S TRAVELS AND THE UNCONSCIOUS}

Gulliver's Travel is an unconscious representation of human nature when we see it as a dream work. Gulliver has seen the horrible evil in human nature through his different imaginative travel destinations, but he certainly comes to realize the change in his character as he passes through all these experiences. Through Gulliver's unconscious experiences with human creatures and semi- human creatures and animals, he realizes the depth of the complexity of human nature, specially the very complicated evil in human behavior. By the end of the novel, we see that Gulliver, himself, has seen the 
wickedness and the dark side of his human nature noting that there is much more humanity in worlds and nations than the nation of the human beings. When he says, "I was amazed to see such actions and behaviors in brute beasts; and concluded with myself, that if the inhabitants of this country were endued with a proportional degree of reason, they must need be the wisest people upon earth." (364)

For example, Gulliver also admits that he has been influenced by the yahoos to a great extent during his stay with them. The frightening thing here, from my point of view, is that Gulliver is probably searching for humanity which he basically could not find in human beings. Adding much complexity to this, he seeks a new identity simply because he has lost his human identity which needs to be replaced with a non-human or animalistic one. If Gulliver's journeys can be seen as escape form humanity because of the lack of humanity, then a non-human identity is possibly the cause behind Gulliver's pursuit and travels. Thus, the novel is an actual social criticism rather than only a political satire simply it amplifies the ills of the society and shows the lack of humanity through a magnifying lens that Swift uses throughout the whole novel. Throughout his fourth trip, Gulliver has carefully observed and criticized the human behavior in his projection on the yahoos.

The dark side of humanity is one of the central issues that Gulliver comes up with, and through this notion, he consistently criticizes the savageness of human or the wicked nature of human being. For example, Gulliver criticizes war, the act of killing, and bloodshed caused by the lack of communication, or the differences in opinions, or the love of authority, he says:

Differences in Opinions hath cost many millions of lives: For instance, whether flesh be bread, or bread be flesh: whether the juice of a certain Berry be blood or wine: whether whistling be a vice or a virtue: whether it be better to kiss a post, or throw it into the fire, what is the best color for a coat, whether black, white, red or grey; and whether it should be long or short, narrow or white, dirty or clean; with many more. Neither are any wars so furious and bloody nor of so long continuance, as those occasioned by difference in opinion, especially if it be in things indifferent. (400)

Swift creates the sense of exoticism through Gulliver's character by showing the human encounter with exotic beings, and then through reversing this encounter with another series of exotic scenes. He puts the reader in a difficult situation where it is hard to see exactly his characters. Gulliver, for example, is a combination of characters, and then the change of his character is seen as a totally reversed makeup. Similarly, he shows us the same images with creatures Gulliver visits. To us, Gulliver has never changed because we are introduced to him since the very outset of his journey, but when he is put away in many different nations, we start to conceive things in totally different ways. Not only Swift uses diminution and magnification techniques, but he also uses alienation as a technique to create far-fetched gothic images. The fantasy he creates is seen as an exotic dream into a very far-fetched world inhabited by beings we have never imagined before. Gulliver is in a middle of nowhere visiting strange nations, with strange names, and strange bodily shapes that maintain a similar system with similar thoughts like human beings humans.

\section{DIMINUTIONANDMAGNIFICATION:ACRITICAL APPROACH}

While Gulliver's Travels tends to create a confusing understanding of criticism, it still gives a good example on the gothic fantasy and supernaturalism. Diminution and magnification create a new understanding of the underlying meaning of the text in light of gothic fantasy. They represent the use of supernatural creatures or semi- human creatures through the two opposite images of Gulliver's character as both a giant and a dwarf. Since diminution and magnification intertwine and work together in different scenes to reflect a reality that can never be completely understood, I think it is valuable here to understand and analyze the text using the gothic as a primary key to the social and the psychological implications of the supernatural images used with both these two critical elements. While it is hard to identify how diminution and magnification play a primary role in showing a reversed reality, I think it is important to analyze the mythologies and the supernatural images embedded in the text which swift heavily used.

The gothic imagery of diminution and magnification also help to understand the hierarchical social and political ladder which the writer obviously shows to us through images of supernatural statures. We simply do not see any normal feature for a human being or creatures as we read through the text. It is only through that alienated picture of human being represented by Gulliver and the nations he visited, we can hardly understand the references to criticism of the social system. There is an interesting parallel between smallness and bigness which vaguely shadows the idea of the sublime. Gigantic things make gothic and supernatural exactly as the small and little things do. In the same way Gulliver is made a huge and gigantic figure surrounded by little beings, he is also made a little and weak dwarf. Gulliver's amazing bodily and physical shape has far exceeded the normal perception about the capacity of a normal human being. What is also interesting in the text is that the fantasy of diminution and magnification are gothic since they tend to create a sense of fear in both cases. Gulliver represents the idea of the sublime in the text in both of his diminutive and magnified stature; his image strikes abnormal or supernatural images of what human being can be.

There is also an interesting parallel that Swift associates with the images of diminution and magnification. There is a big focus on the body along with the imagined fantasy of Gulliver's World. Swift makes Gulliver's body the central driving force that poses a confusing reality simply because the image of Gulliver's stature has also changed in proportion with the nations he visited. Part of this concentrated emphasis on the body appears when Gulliver succeeds to threaten the whole Lilliputians nation through his body which causes fear and panic for the whole nation. Despite the peaceful nature of Gulliver, unlike the monstrous appearance of giants and monsters in the gothic fantasy in general, his body continues to threaten the Lilliputians system of life including the ruling system. Interestingly enough, Swift uses magnification to show us a 
close picture of the horrors of the physical objects including Gulliver's body when he highlights the horror images of the body waste that create a real sanitation problem for the whole nation. Therefore, Gulliver is made a source of phobia as his abnormal body stature threatens what is conceived as normal body stature from the Lilliputians' point of view.

\section{THE GOTHIC FANTASY IN SWIFT'S GULLIVER'S TRAVELS}

Part of the gothic fantasy that Swift draws in Gulliver's Travels is familiarity vs. the exotic as it is clearly shown in all of Gulliver's journeys. However, Swift makes the gothic in Gulliver's Travels encapsulated with a human sense, and in order to approach that gothic element, he clearly manipulates Gulliver's body. As Hinnant notes, "The Human sense of defilement appears at precisely that juncture when higher and lower levels are sufficiently distinct for them to be clearly contrasted (i.e. perfection vs. depravity), while still appearing to be inseparable (i.e. equally natural). A similar sense of impurity emerges whenever human conduct becomes the object of scrutiny and integration while not being regarded as fully human." (6)

While Swift tries to pose this gothic image of human nature represented by Gulliver's body and the creatures he sees, this representation, however, goes beyond the rational sense but it is only visible through Swift's magnifying lens:

Gulliver's role as voyager and witness in Gulliver's Travels, like the role of the narrator in exotic voyage literature, acts as a unifying force; authenticating the details and making them seem actual. But swifts alter the exotic narrator's traditional eyewitness role; for in three of the four voyages, Gulliver, like the haunted figure of the castaway narratives, is thrust into abnormal situations where he is attacked, risks his life and is integrated into the world of the other characters instead of remaining an independent observer, yet because of his position as a stranger, an outsider, an individual whose origin are unknown and who possesses extra ordinary characteristics, Gulliver never becomes fully assimilated into these worlds, but tends to be isolated as impure, as focus for the anger, fear and anxieties of their inhabitants.(9)

It is noticeable that Swift not only makes Gulliver as an alien to the nations he visits but he rather makes him alien to us as readers simply because we are introduced to very little details about Gulliver. He is introduced to us as a man travelling to nowhere and put in a middle of swirling nightmares in a very far away exotic place with exotic semi-human creatures. While Swift creates an enigmatic fantasy using these techniques, he associates this fantasy with an extended series of gothic structures and images. However, these images and structures are put in a shadow where we can hardly say for sure how to decompose these structures in light of the gothic. Swift brings new images others have not brought in the literary canon before. Despite the fact that images like semi-human creatures, or talking horses, might have been seen in Greek mythology, I still think that Swift brought totally new astonishing gothic images that no one has touched before, such as the Yahoos as an example. From this point, Swift's
Gulliver's Travel might meet some of the dynamics and elements of the gothic as a genre despite the huge discrepancy of thoughts and criticism we see among the many scholarly views written about Gulliver's Travels that only open a kind of closure to the understanding of Gulliver's Travels as being only Satire. I do not diminish the possibility of reading Gulliver's Travels as satire, and I would definitely take it as satire, but reading Gulliver's Travels in a different way apart from satire made me think of it as a gothic fantasy having in mind the complexity of the structures swift makes in his novel. Monk in "The pride of Lemuel Gulliver" clarifies

The idea that man occupies anomalous, a middle, state in creation was a familiar one in Swift's day. The whole of living [54] creation was conceived to be carefully ordered and subtly graded in one vast "chain of being", descending from God through an almost infinite number of pure intelligences, to man, and thence through the lower animals to microscopic forms of life, which finally ends in nothing. Man occupies the most uncomfortable position in this chain, since to a limited degree he shares the intelligence of higher creature, and to unlimited degree the sensuality of animals. He is the middle link because he is the transitional point between the purely intelligent and the purely sensual. With pope, with Addison, and a number of other writers this image, for reason which we shall not inquire into, became one of the chief support of the optimism of the enlightenment-optimism concerning God, nature, and Man. (232) Gulliver's Travels also coincides with the idea of the sublime, especially if we compare gigantism with dwarfism Swift is creating a huge gap between these two dimensions to give the sublime the chance to rise on the surface. Interestingly enough, the sublime is correlated with the threat and danger. The Lilliputians fear the existence of the gigantic body in their nation. Despite the fact that Gulliver is a persistent watcher and observer of the two nations, we see him as a little weak dwarf who fears the gigantism of others. Quintana in "From the Mind and Art of Jonathon Swift" says:

The equivalence between irrational man and yahoo is established with great skill. Gulliver has scarcely been put assure by his mutinous crew and has not yet met with any of the noble Houyhnhnms when he is set upon by some forty of the most loathsome creatures he has ever seen. Describing them at length, he remarks, "I never beheld in all my travels so disagreeable an animal, or one against which I naturally conceived so strong an antipathy," but in this first encounter he perceives nothing of their resemblance to himself. It is only after he has been led home by a Houyhnhnm, who takes him into the courtyard and compares him with one of the yahoos tied up there that grasps their similarity to men, observing with horror and astonishment a perfect human figure in this abominable animal. (115)

The sublime in Gulliver's Travels not only poses a restricted view of threat and danger, but, it also poses the danger of control and authority even though the giant is made not as clever as the dwarf in the novel. While Gulliver's Travels provides the sublime fantasy throughout the whole 
novel, we can see how that the sublime fantasy is associated with political and social criticism of the human social behavior referring to materialism, dehumanization, and cruelty of human nature. It is noticeable that in both of these two nations, swift gives a morbid picture of human behavior signifying the cruelty of human nature. For example, Gulliver in his diminuend stature has to suffer the mockery people make on him. This shows us how the human nature can be at its worst scenario when materialism associates that gigantism which signifies greediness. As we see in this example, when Gulliver is put in the market for the show, he says:

For my own part I may truly affirm that I was less concerned than my nurse. I had a strong hope which never left me that I should one day recover my liberty; and as to the ignominy of being carried about for a monster. I considered myself to be a perfect stranger in the county; and that such a misfortune could never be charged upon me as a reproach if ever I should return to England; since the king of Great Britain himself in my condition must have undergone the same distress. (138)

What escalates the possibility of the gothic scheme in Gulliver's Travels, from my point of view, is the possibility of including Ovid's metamorphosis, which is one of the basic elements in the gothic fantasy. Guilhamet, in fact, refers to the Ovidian influence in Gulliver's Travels in Satire and the transformation of Genre, when he says, "Transformations, some explicitly Ovidian, are very common in formal satire. Swifts' Baucis and Philemon (1709) is a direct imitation of Ovid which transforms itself into a satire as the homely couple experiences a series of metamorphosis. The translation of Shadwell to the throne of Dullness, of Belnda into termagant, and of Gulliver to Houyhnhnm postulant are just a few of transmutations that satire record. Formal social occasion such as a coronation, a trip to Hampton Court, or a symposium, provides an appropriate setting in which to chronicle the human Kaleidoscope." (44)

Having the idea of metamorphosis in mind, I think that looking at Gulliver's Travels from this perspective allows us to see the gothic structure in Gulliver's Travels that cannot be isolated from the social or political context of the novel. However, understanding the gothic scheme in Gulliver'sTravels might also help understand satire in general, if we consider the notion that a lot of gothic works have to do with social, political and even psychological anxieties of the society. Gulliver's Travels is no exception to this. Gulliver's Travels takes part of the gothic fantasy to introduce new possibilities in the gothic world other than the prevalent conventional gothic modes in terms of imagination, multiple-plots, character and even settings and names. In this case, Gulliver's Travel with its new satirical transformations brings new attachments to the gothic fantasy. Possibly, this is the angle from which we can see the association between the gothic fantasy and Gulliver's Travels as we discover real new forms and contents. This matches what Day think of the characteristics of the gothic fantasy in In the Circles of Fear and Desire, when he explains:

The gothic fantasy is the intermediary between the world it describes and the conventional world, which is fundamentally different in form and structure. Indeed the Gothic World, which is in the gothic fantasy the world beyond death, has no form or shape of its own. It is unknowable in conventional terms. It is made manifest in a kind of translation, in which that which is unnamable and unknowable is given name and form, made knowable through the conventional language of narrative. The gothic fantasy describes in terms of characters, actions, and plots a world that has none of these things. It defines not the whole of the underworld, but that part we can comprehend. (14)

Diminution and magnification carry different possibilities and interpretations. Gulliver's presence strikes fear and terror in the Lilliputians' nation as being a source of threat, danger, and death. Hinnant suggests in purity and defilement in Gulliver's Travels that Gulliver is a clear and visible representation for the fears and anxieties of the Lilliputians; he says, "In the first voyage, Swift's shift in perspective transforms Gulliver into an inevitable and obvious focus for the fears and anxieties of the Lilliputians. Because of his size, Gulliver is seen by the Lilliputians not only as an obvious danger but also as a potential source of contagion and defilement." (18

Interestingly enough, the gothic and supernatural imagery matches the political satire embedded in the text. Gulliver's gigantic body causes fear to Lilliputians because his body looks exotic, fearful and strange, it is different from the physical bodies they have. The fear of the body as being gothic is actually rooted deep in mythology and the gothic fantasy as well. Gulliver's huge gigantic body does not, particularly, threaten the political and social system of the Lilliputians, but it also causes the fear of destruction of the whole nation. It is the physical power that lies in the body that causes that fear for the Lilliputians. The Lilliputians do not feel comfortable with the huge strange body they have in their land because it looks dangerous and fearful and even it foreshadows the change in the social and moral structure of the society.

The diminution also serves as a strategy to highlight the negative and hidden side of things that actually look normal and familiar to the human eye. It is important here to see how the ugly and gothic parts of little things just appear so visible in Swift's world. He used this technique to show that fear could arise from the things we might think of as little and peaceful. In one of the scene we see Gulliver the dwarf fights the wasps, but then those wasps at that point are not actually normal in the human sense, but they are so frightening, scary and ugly. The magnification here serves to enlarge the invisible picture that we can't commonly see from the human sense or we do not actually give them much attention, but they cause fear just as much as the big and giant things do. Magnificati $\mathrm{n}$ here stands as an important technique to understand the realities that are hidden somewhere in little things. As we notice in this passage when Gulliver had fight the wasps:

I remember one morning when Glumdalclitch had set me in my box upon a window, as she usually did in fair days to give me Air, (for I durst not venture to let the box 
be hung on a nail out of the window, as we do with cages in England) after I had lifted up one of my sashes, and sat down at my table to eat a piece of sweet cake for my flying into the room, humming louder that the drones of as many bagpipes. Some of them seized my cake, and carried it piecemeal away; others flew about head and face, confounding me with the noise, and putting me in the uttermost terror of their stings. However, I had the courage to rise and draw my hanger, and attack them in the air. I dispatched four of them, but the rest got away, and I presently shut my window. These insects were as large as partridges; I took out their stings, found them an inch and half long, and sharp as needles. I carefully preserved them all and having since shown them with some other curiosities in several parts of Europe; upon my return to England I gave three of them to Gresham College, and kept the fourth for myself (163).

\section{CONCLUSION}

It is quite obvious that these techniques of magnification and diminution tend to either alienate the image of human being in an exotic place with exotic creatures, or simply picture the human image from both an imaginative perspective. There is much focus on little things that we can see clearly in Gulliver as a human being. The macroscopic image of Gulliver is presented and magnified to enla ge the terror of reality. From my point of view, Swift is giving the reader the sense that there are many ways in which you can approach the human existence, but definitely the reality is still far beyond our own perception. Hinnant refers to that fear when he talks about the obsession the Lilliputians have about Gulliver's body, he says:

Seen from this perspective, the first voyage maybe read as an ironic fable of a society riddled by fear, its theme the baleful consequences of this fear on its laws and institutions. The theme is reflecte not only in the pretty intrigues, jealousies, rivalries and conflicts of the Lilliputians, but also in the inflexibility of their taboos on bodily discharges, taboos that reflect their obsessions concerning the entrance of dangerous impurities into their system. In swift's satire the model of the human body becomes a doubly appropriate symbolic focus for the anxieties of the Lilliputians concerning a violent faction at home, and the danger of an invasion by a most potent enemy from abroad. (20)

It is important to note here that Gulliver's Travel is not just a fantasy and a fiction, but it rather serves to provide cultural and social messages about the anxieties people have. It is more like a journey into the unconscious dream that represents the worries about the human physical life and the intellectual part of human existence. As Day notes, "The gothic fantasy is a realm created by the human imagination, into which the human imagination retreats. Nevertheless, it also represents the alienation of the human imagination from its own products. To escape anxiety and terror, the imagination creates fantasies of anxiety and terror; the experiences that cause our alienation reappear in our escapes from it. The human world dramatized in the gothic fantasy is a history less, order less abyss. Thus, not only is the human world alienated from the visions of science and myth, but it is also profoundly self-alienated. In gothic fantasy, the human imagination can only externalize the fears it finds in itself." (42

Finally, I think that Gulliver's Travels is a good example on how imagination plays a role in escaping cultural anxieties and then remodeling these worries into dreams and fantasies that modify new ways to look at human existence. I think that reading Gulliver's Travels from this perspective would give a better view about the profound unconscious meaning of the text, especially if we consider Gulliver's Travels as a gothic fantasy.

\section{REFERENCES}

Hinnant, Charles H. Purity and Defilement in Gulliver's Travels. New York: St. Martin's, 1987. Print.

Foster, Milton P. A Casebook on Gulliver among the Houyhnhnms. New York: Crowell, 1961. Print.

Felman, Shoshana. Literature and Psychoanalysis. Baltimore: Johns Hopkins UP, 1982. Print.

Knowles, Ronald. Gulliver's Travels: the Politics of Satire. New York: Twayne, 1996. Print.

Stringfellow, Frank. The Meaning of Irony: a Psychoanalytic Investigation. Albany, NY: State University of New York, 1994. Print.

Lemke, Donald B., Cynthia Martin, Benny Fuentes, and Jonathan Swift. Jonathan Swift's Gulliver's Travels. Minneapolis: Stone Arch, 2008. Print.

Palmeri, Frank. Critical Essays on Jonathan Swift. New York: G.K. Hall, 1993. Print.

Parkin-Gounelas, Ruth. Literature and Psychoanalysis: Intertextual Readings. Houndmills, Basingstoke, Hampshire: Palgrave, 2001. Print. 